Research Paper

\title{
Magnesium aminoclays as plasmid delivery agents for non-competent Escherichia coli JM109 transformation
}

\author{
G.P. Mendes ${ }^{\text {a,b,* }}$ L.D. Kluskens ${ }^{a}$, S. Lanceros-Méndez ${ }^{\text {b,c,d }}$, M. Mota ${ }^{\text {a }}$ \\ ${ }^{a}$ Center of Biological Engineering, University of Minho, Campus de Gualtar, 4710-057 Braga, Portugal \\ ${ }^{\mathrm{b}}$ Center of Physics, University of Minho, Campus de Gualtar, 4710-057 Braga, Portugal \\ ${ }^{\mathrm{c}}$ BCMaterials, Basque Center for Materials, Applications and Nanostructures, UPV/EHU Science Park, 48940 Leioa, Spain \\ ${ }^{\mathrm{d}}$ IKERBASQUE, Basque Foundation for Science, 48009 Bilbao, Spain
}

\section{A R T I C L E I N F O}

\section{Keywords:}

Magnesium aminoclays

Membrane permeation

Microorganism transformation

Nanobiohybrid complex

Plasmid delivery

\begin{abstract}
A B S T R A C T
Magnesium aminoclays were synthesized and used to transform non-competent Escherichia coli JM109 using the exogenous plasmid pUC19. The structure determined for the $\mathrm{Mg}$ aminoclays is analogous to 2:1 trioctahedral smectites such as talc, with an approximate composition $\mathrm{R}_{8} \mathrm{Si}_{8} \mathrm{Mg}_{6} \mathrm{O}_{16}(\mathrm{OH})_{4}$, where $\mathrm{R}=\mathrm{CH}_{2} \mathrm{CH}_{2} \mathrm{NH}_{2}$, morphologically arranged in layered sheets. $\mathrm{Mg}$ aminoclays were employed as a cationic vehicle that enabled the passage of plasmids across the cell envelope and led to genetic modification of the host. A stock solution of 10 $\mathrm{mg} / \mathrm{mL}$ of $\mathrm{Mg}$ aminoclays was prepared, mixed with E. coli JM109 and pUC19 plasmid, and spread over Petri dishes containing lysogeny broth (LB), isopropyl $\beta$-D-1-thiogalactopyranoside (IPTG), 5-bromo-4-chloro-3indolyl- $\beta$-D-galactopyranoside (X-gal), ampicillin and various concentrations of agar (1-4\%). The transformation efficiency obtained was higher for $1 \%$ and $2 \%$ agar even though transformation also occurred at agar concentrations of $3 \%$ and $4 \%$. The optical density of E. coli JM109 and spreading time were also adjusted, favoring transformation when cells were used in their exponential growth phase $\left(\mathrm{OD}_{600}=1.0\right)$ and spread for $90 \mathrm{~s}$. Transformation was confirmed by the growth of blue colonies in LB/IPTG/X-gal/agar Petri dishes containing ampicillin, by regrowth of biomass in liquid media containing ampicillin and by agarose gel electrophoresis of the linearized pUC19 plasmid that followed plasmidic DNA extraction from 4 blue colonies. The maximum transformation efficiency achieved was $7.0 \times 10^{3} \mathrm{CFU} / \mu \mathrm{g}$ pUC19. This transformation approach proved to be suitable for a convenient, cost-effective, room-temperature, risk-free and rapid transformation of non-competent E. coli JM109.
\end{abstract}

\section{Introduction}

Genetic modification or transformation of microorganisms, perceived as a consequence of an intake of external DNA with the purpose of originating cells capable of producing interesting compounds for the pharmaceutical, food or energy sectors, is a fundamental process for promoting advances in biotechnology and is still predominantly accomplished through heat-shock or electroporation. However, these techniques share the disadvantage of requiring the preparation of competent cells causing them to become inconvenient and timeconsuming procedures. Electroporation in particular has the added inevitability of manipulation of cuvettes that must be submitted to dangerous high-voltages and are ephemeral expensive consumables. Even in more convenient cases contemplating the acquisition or freeze- storage of competent cells that can efficiently be transformed with a specific plasmid by these techniques, transformation using other plasmids is not guaranteed. Furthermore, several species of bacteria and yeast with great potential for biotechnology applications are completely recalcitrant to any lab-induced genetic modification through these or any other of the less frequent transformation methods available (Ren et al., 2019). Therefore, efficient emergent alternative transformation methods and their optimization resulting in routine laboratory protocols are crucial to unravel the potential of recombinant DNA technology which stimulates the development of the field of biotechnology. Novel delivery agents have recently been developed such as a cationic fusion peptide that penetrates Escherichia coli enabling the expression of a large-sized plasmid (pMSR227, 205 kb) (Islam et al., 2019) and arginine-glucose functionalized hydroxyapatite nanoparticles, that can

\footnotetext{
* Corresponding author at: Center of Biological Engineering, University of Minho, Campus de Gualtar, 4710-057 Braga, Portugal.

E-mail address: gabriel.mendes@dep.uminho.pt (G.P. Mendes).
} 
be used for transformation of at least one Gram-negative and one Grampositive bacterial species (Deshmukh et al., 2019a) and one species of yeast (Deshmukh et al., 2019b) with high transformation efficiencies.

Advances in the application of synthetic nanostructured materials produced by wet-chemistry strategies have recently been accomplished in various fields such as photocatalysis (Morassaei et al., 2017; ZinatlooAjabshir and Salavati-Niasari, 2017), energy storage (Ghodrati et al., 2020; Mousavi-Kamazani et al., 2020) or selective catalytic reduction (SCR) (Zinatloo-Ajabshir et al., 2021). In particular, wet-chemistry has been used to produce clays containing organic groups which have been investigated with great detail during the last couple of decades due to their potential use in smart materials (Zhuk et al., 2011), batteries (Zhang et al., 2008), polymer engineering (Ruiz-Hitzky et al., 2005), protective barriers (Yao et al., 2012), nanocomposites, (Balazs et al., 2006; Podsiadlo et al., 2007; Bonderer et al., 2008; Munch et al., 2008; Priolo et al., 2010), immobilization of catalysts (Miao et al., 2006; Scheuermann et al., 2009), purification of mixtures (Ding and Henrichs, 2002; Hsu et al., 2010), tissue engineering (Pappas et al., 2007; Liu et al., 2013, 2014), targeted drug delivery (Viseras et al., 2010) and several other biological and environmental applications (Bui et al., 2018). The synthesis of functional clays capable of specific interaction with cells, molecules or substrates is expected to be advantageous for many new in vivo applications. Consequently, a new class of synthetic clays with organic-inorganic layers derivatives of 2:1 trioctahedral phyllosilicates has been developed, possessing amino functionalized propyl groups occupying the interlayer locations (Burkett et al., 1997; Mann et al., 1997). These aminoclays can be prepared through a simple protocol using an organosilane precursor and magnesium or calcium chloride at room-temperature through a sol-gel process. Nanobiohybrid inorganic compounds can be easy prepared using aminoclays by incorporating functional biomolecules, bearing potential for applications as biocatalysts (Lee et al., 2013), biosensors (Mann, 2009; Mousty, 2010) or drug delivery nanocarriers (Patil et al., 2005; Patil and Mann, 2008; Chaturbedy et al., 2010). Additionally, the positive charges from the amino groups of the aminoclay nanoparticles at physiological $\mathrm{pH}$ values makes them excellent candidates for electrostatic binding with DNA (Whilton et al., 1998; Datta et al., 2013) and diffuse as a complex through an aqueous environment without substantial adverse aggregation. Certain clay mineral nanomaterials and particularly aminoclays have been reported as acting as a bactericide (Williams et al., 2011; Ito et al., 2018; Abhinayaa et al., 2019; Gaálová et al., 2019; Li et al., 2019). The bactericidal activity of aminoclays is a consequence of the easy adsorption of the aminoclays onto bacterial cell surfaces followed by penetration of the cell wall and membrane(s), leading to membrane damage, depolarization, leakage of intracellular components and cell death (Chandrasekaran et al., 2011), but cell survival can potentially be controlled by adjusting the concentration of aminoclays that the microorganisms are exposed. Aminoclays have also already been reported to have low toxicity while being effective as a cationic vehicle for enhancing adenovirus-mediated gene transfer in mammalian cells (Kim et al., 2017). Accordingly, delivery of plasmids bound to aminoclays to the interior of a vast range of different species of microorganisms can potentially be achieved using an aminoclay concentration under a threshold that ensures host survival and having the exogenous plasmid protected from restriction enzymes due to a self-assembled nanoarmor (Demanèche et al., 2001). Moreover, Mg aminoclays have already successfully led to the expression of plasmids in E. coli XL1-Blue and Streptococcus mutans (Choi et al., 2013) and in Paenibacillus riograndensis and Paenibacillus polymyxa (Brito et al., 2017), exhibiting potential to be used for transformation of other microorganisms that are recalcitrant to be modified genetically by conventional methods.

The main scope of this work was to synthesize Mg aminoclays via a simple sol-gel process, characterize and explore their use as a vehicle to deliver the plasmid pUC19 across the cell envelope of a non-competent version of a laboratory workhorse widely used as cloning host, Escherichia coli JM109, and refine different conditions towards achieving maximum transformation efficiency. The work thus allows to evaluate the potential of an alternative approach for bacterial transformation, which represents an easy and rapid solution that can prevail for many common laboratory needs. This work can also be used as reference for future transformation attempts on other microorganisms and stimulate the adoption of plasmid delivery agents as a strategy to transform recalcitrant species relevant to the field of biotechnology.

\section{Materials and methods}

\subsection{Preparation of $\mathrm{Mg}$ aminoclays}

The protocol for preparation of $\mathrm{Mg}$ aminoclays followed the sol-gel approach reported in literature (Han et al., 2011; Lee et al., 2013a; Kim et al., 2014, 2017). Initially, a 0,2065 M solution of magnesium chloride hexahydrate (Sigma Aldrich, $\geq 99.0 \%, 1.68 \mathrm{~g}, 8.26 \mathrm{mmol}$ ) in ethanol (Panreac, $\geq 99.8 \%, 40 \mathrm{~mL}$ ) was prepared in a beaker by adding the salt to the alcohol and stirring. After complete dissolution of the salt, 3-aminopropyltriethoxysilane (APTES) (Sigma Aldrich, $\geq 98 \%$; $2.6 \mathrm{~mL}$, $28.10 \mathrm{mmol}$ ) was injected by hand using a syringe to the previous solution under stirring. A white slurry was obtained after the injection of APTES. The reactant solution was stirred overnight. Then, the product was washed two times by centrifugation with ethanol $(200 \mathrm{~mL})$ to remove excess cationic magnesium metals. The sample was dried at $40{ }^{\circ} \mathrm{C}$ for $24 \mathrm{~h}$. Before preparation of the aminoclay solution in distilled water, the dried synthesized material was grinded with a pestle and mortar resulting in a white fine powder.

\subsection{Mg aminoclays characterization}

Transmission electron microscopy (TEM) measurements were performed on a JEOL 200CX (200 kV) microscope. TEM samples were prepared by dissolving $\mathrm{Mg}$ aminoclay powder in distilled water $(2.5 \mathrm{mg} /$ $\mathrm{mL}$ ) through sonication during $15 \mathrm{~min}$, followed by room-temperature evaporation of a drop of this suspension on a carbon film coated grid.

Attenuated total reflection - Fourier transform infra-red (ATR-FTIR) spectroscopy was performed on a Thermoscientific NEXUS 8700 FTIR spectrometer (Thermo Nicolet, Inc.). Spectra were recorded over the wavenumber range between 4000 and $500 \mathrm{~cm}^{-1}$ at a resolution of 2 $\mathrm{cm}^{-1}$ and are reported as the average of 64 spectral scans. All samples were dried under vacuum to evaporate any remaining solvent or moisture previously to measurement.

The crystal structure and purity of the Mg-aminoclays were evaluated by powder X-ray diffraction (XRD) measurements in a Rygaku/Max System RU 300 diffractometer using $\mathrm{Cu} \mathrm{K} \alpha$ incident radiation (scan speed: 1.25 s per step, step size: $0.02^{\circ}, 50 \mathrm{kV}, 40 \mathrm{~mA}$ ).

The average hydrodynamic diameters and $\zeta$ (zeta) potentials of the nanoparticles were measured on a Zetasizer Nano ZSZEN3600 (Malvern Instruments Limited, U.K.), equipped with a $\mathrm{He}-\mathrm{Ne}$ laser (wavelength $633 \mathrm{~nm}$ ) and a detection angle of $173^{\circ}$ (backscatter detection). Measurements were performed at $25^{\circ} \mathrm{C}$ at the appropriate sample dilution in ultrapure water to hinder multiscattering events. Zetasizer 6.20 software was used to estimate particle mean diameters from the intensityweighted distributions (size), polydispersity index (PDI), and $\zeta$-potential values.

\subsection{Assays for transformation of E. coli JM109 with pUC19 plasmid using $\mathrm{Mg}$ aminoclays}

Petri dishes were prepared by autoclaving lysogeny broth (LB) $2 \%$ and agar $1-4 \%$ in distilled water and after cooling to about $45{ }^{\circ} \mathrm{C}$ isopropyl $\beta$-D-1-thiogalactopyranoside (IPTG), 5-bromo-4-chloro-3indolyl- $\beta$-D-galactopyranoside (X-gal), both purchased from Nzytech, and ampicillin purchased from Fisher Scientific, were added to final concentrations of $1 \mathrm{mM}, 40 \mu \mathrm{g} / \mathrm{mL}$ and $100 \mu \mathrm{g} / \mathrm{mL}$, respectively. The amount of agar/LB used per Petri dish was $15 \mathrm{~mL}$. Before each 
experiment, Petri dishes were dried for $20 \mathrm{~min}$ to remove moisture. In a typical experiment a 50 -fold dilution of an overnight culture $(200 \mathrm{rpm}$, $37^{\circ} \mathrm{C}$ ) of non-competent $E$. coli JM109 was used. Following growth until a certain optical density, $500 \mu \mathrm{L}$ of E. coli JM109 per Petri dish were centrifuged at $16162 \mathrm{~g}$ for $3 \mathrm{~min}$ and the supernatant was decanted. Then, to $100 \mu \mathrm{L}$ per Petri dish of $\mathrm{Mg}$ aminoclays $0.1,1$ or $10 \mathrm{mg} / \mathrm{mL}$ in distilled water, $10 \mu \mathrm{L}$ of $50 \mathrm{ng} / \mu \mathrm{L}$ of pUC19 was added and vortexed for $1 \mathrm{~min}$. Concentrations of $\mathrm{Mg}$ aminoclays above $10 \mathrm{mg} / \mathrm{mL}$ led to a visible precipitation of the $\mathrm{Mg}$ aminoclays and were not used. The cells were resuspended by the Mg aminoclays/pUC19 solution through vortexing for $1 \mathrm{~min}$ and spread on Petri dishes with a polystyrene spreader, typically for 30,60 or $90 \mathrm{~s}$. Petri dishes were then incubated overnight at $37^{\circ} \mathrm{C}$ to promote growth of colonies. The following day, the amount of blue transformants was quantified using an Interscience Scan 300 automatic colony counter and the transformation efficiency was determined. Five replicas of each experiment were performed, and the highest and lowest counts of colonies were eliminated to diminish the standard deviation observed, so the graphs presented are taken from values in triplicate. Plasmid DNA extraction was accomplished with a Nucleospin (NoLid) kit from Macherey-Nagel and submitted to analysis by agarose gel electrophoresis (1\%).

\subsection{Statistical analysis}

To assess statistical differences, a one-way ANOVA test was used. For determining differences among means, a Tukey honest significant test was performed as required. Differences were considered significant for $P$ values $\leq 0.05 . *=0.05 \geq P>0.01 ; * *=0.01 \geq P>0.001 ; * * *=P \leq$ 0.001 . All tests were performed using Graphpad Prism analysis package.

\section{Results and discussion}

Escherichia coli JM109 has been one of the most popular hosts in recombinant DNA technology for cloning and expression of plasmids and was selected in this work as a model for fine-tuning the conditions maximizing a possible transformation with plasmidic DNA using $\mathrm{Mg}$ aminoclays as delivery agents due to its versatility, robustness and availability of data in the literature. Aminoclays functionalized with divalent cations such as $\mathrm{Mg}$ have been shown to destabilize the cell envelope of both Gram-negative and Gram-positive bacteria (Chandrasekaran et al., 2011; Lee et al., 2013a), revealing promising properties for being used to deliver biomolecules to the interior of microorganisms and be adopted as a conventional material for routine transformations as an alternative to heat-shock or electroporation. Finetuning transformation conditions with a non-competent version of the host chosen in this work is essential due to the preferred adoption of E. coli JM109 for many recombinant DNA technology purposes and the promising benefits of avoiding the need of competent cells for transformation through an advantageous procedure. Furthermore, similar conditions can be adapted and used for future transformations attempts on other microorganisms.

\subsection{Mg aminoclays characterization}

As shown in the transmission electron microscopy (TEM) image of Fig. 1, Mg aminoclays possess layered structures, corresponding to the typical layout present in clay materials. In aqueous solution, aminoclays were protonated to form $-\mathrm{NH}_{3}^{+}$forms, and then immediately delaminated (i.e., exfoliated) by electrostatic repulsion to disperse as single or a few layered sheets (Fig. 1). The dried average diameter of Mg aminoclay nanoparticles, revealed by TEM and shown by this high magnification representative example, emphasize that the layered sheets exhibited a size range of $30-180 \mathrm{~nm}$ in diameter, forming fuzzy aggregates that lead to difficulties in focusing when visualizing by low magnification TEM as reported by Kim et al. (Kim et al., 2014). Overall, the Mg aminoclay nanoparticles are hydrophilic and possess protonated $\left(\mathrm{R}^{-\mathrm{NH}_{3}^{+}}\right)$groups,

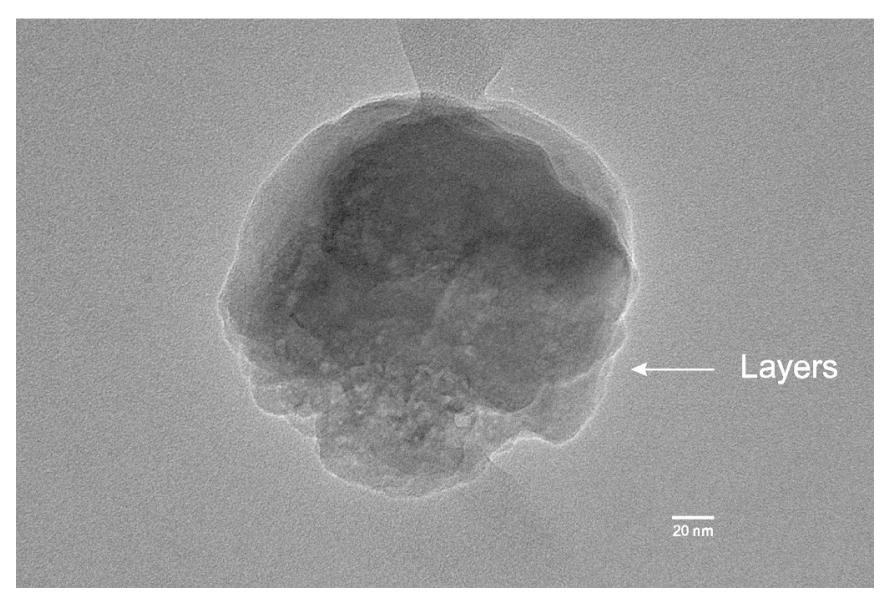

Fig. 1. TEM image of an $\mathrm{Mg}$ aminoclay nanoparticle air-dried from a dispersion in distilled water at a concentration of $2.5 \mathrm{mg} / \mathrm{mL}$. Scale bar is $20 \mathrm{~nm}$. Note: Arrow indicates the layers of the organo-(phyllo)silicate particle's edge.

which create a number of bonding sites for ion exchange within the interlayer spaces and serve as surface groups on the lamella, which are driven by electrostatic forces formed at the dual-end pendant amino groups as has been reported previously by Lee et al. (Lee et al., 2013a).

The dynamic light scattering (DLS) measurements of $\mathrm{Mg}$ aminoclays in ultrapure water exhibited a size distribution represented in Fig. 2a, with a polydispersivity index of 0.299 and an average size by intensity of $38.17 \mathrm{~nm}$. These results fit well with the TEM observations (particles having $30-180 \mathrm{~nm}$ ) since DLS is assuming spheres and $\mathrm{Mg}$ aminoclays are made of sheets with almost no thickness. DLS will always provide a smaller average size as $\mathrm{Mg}$ aminoclays are disk-like structures and not spheres, so the TEM and DLS results do match well. Furthermore, these results are in line with the data obtained by Han et al., in which $\mathrm{X}_{10}, \mathrm{X}_{50}$ and $X_{99}$ (the cumulative particle hydrodynamic size at 10, 50, and 99\%) of Mg aminoclay displayed 35.86/44.31/64.60 nm (Han et al., 2011).

The Mg aminoclays present positive zeta potential at all $\mathrm{pH}$ values tested (Fig. 2b). Positive charge is fundamental for the electrostatic binding of plasmids which are negatively charged. Considering the small amount of DNA used in a typical transformation experiment (ratio $\mathrm{Mg}$ aminoclays/pUC19 2000:1 wt/wt) the presence of plasmid is not expected to contribute significantly to the magnitude and profile of the zeta potential regarding implications on the interaction of the DNA-Mg aminoclay complexes with bacteria. This is substantiated by the data of Kim et al., which performed zeta potential measurements with hydrated $\mathrm{Mg}$ aminoclay/DNA mixtures and observed a $8.8 \mathrm{mV}$ decrease on the absolute zeta potential value when compared to samples composed exclusively of hydrated Mg aminoclays (Kim et al., 2014). The decrease in zeta potential presented in this work is expected to be lower since the ratio of $\mathrm{Mg}$ aminoclays/DNA that was used in a typical transformation assay is 3 times higher than the one used by Kim et al. Nevertheless, even if a similar decrease in the magnitude of the zeta potential would be attained due to the presence of DNA, the whole zeta potential profile under the $\mathrm{pH}$ range tested would still remain positive and the nature and consequences of the interaction of the $\mathrm{Mg}$ aminoclays with bacteria maintained. In normal conditions, the cell wall of Gram-negative bacteria is negatively charged due to the presence of lipoteichoic acid, lipoproteins and lipopolysaccharides (Chandrasekaran et al., 2011). The positively charged aminopropyl moiety of $\mathrm{Mg}$ aminoclays thereby interacts with the cell wall of $E$. coli JM109, culminating in its fracture and consequent release of plasmidic DNA into the interior of the cell, probably by exchange with RNA and/or low molecular weight metabolites in the cell (Yoshida and Ide, 2008) which is then followed by plasmidic gene expression, although more robust evidence is required to ensure that this mechanism is correct.

The Attenuated total reflection - Fourier transform infra-red (FTIR 

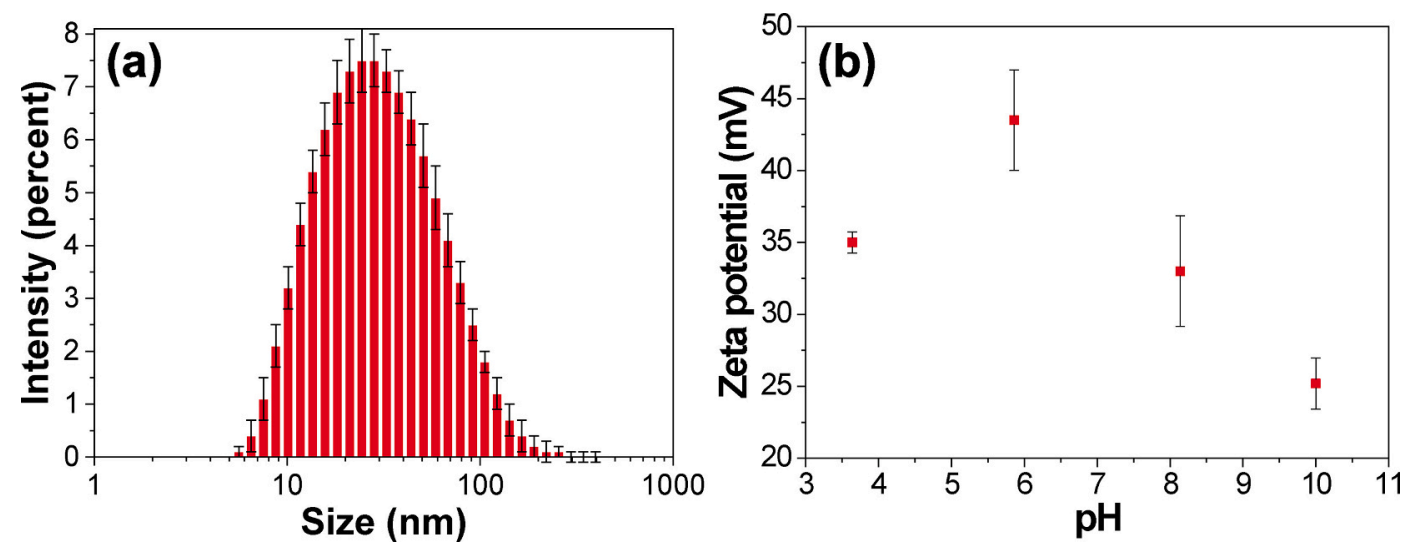

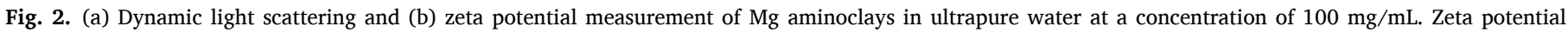
measurement was performed by addition of drops of $0.1 \mathrm{M} \mathrm{NaOH}$ or $\mathrm{HCl}$, providing variation of $\mathrm{pH}$.

-ATR) spectra of the Mg clay (Fig. 3a) contained peaks corresponding to the following functional groups: $\mathrm{OH}\left(3384 \mathrm{~cm}^{-1}\right), \mathrm{CH}_{2}$ peak $(3000$ $\left.\mathrm{cm}^{-1}\right), \mathrm{NH}_{3}^{+}\left(2007 \mathrm{~cm}^{-1}\right), \mathrm{NH}_{2}\left(1607 \mathrm{~cm}^{-1}\right), \mathrm{Si}-\mathrm{C}\left(1144 \mathrm{~cm}^{-1}\right), \mathrm{Si}-\mathrm{O}-\mathrm{Si}$ $\left(1130 \mathrm{~cm}^{-1}\right), \mathrm{Si}-\mathrm{OH}\left(1034 \mathrm{~cm}^{-1}\right), \mathrm{Mg}-\mathrm{O}-\mathrm{Si}\left(849 \mathrm{~cm}^{-1}\right)$, Si-O-C (849 $\left.\mathrm{cm}^{-1}\right)$, and $\mathrm{Mg}-\mathrm{O}\left(559 \mathrm{~cm}^{-1}\right) . \mathrm{Mg}$ aminoclays formed covalent bonds with the metal ion and organo-functionalities, further $-\mathrm{NH}_{2}$, and protonated $-\mathrm{NH}_{3}^{+}$peaks appeared and were in good agreement with earlier reports (Lee et al., 2010). Additionally, X-ray diffraction (XRD) experiments (Fig. $3 \mathrm{~b}$ ) reveals peaks corresponding to $2 \theta=6.61^{\circ}\left(\mathrm{d}_{001}\right) ; 2 \theta=$ $23.83^{\circ}\left(\mathrm{d}_{002}, \mathrm{~d} 110\right) ; 2 \theta=36.31^{\circ}\left(\mathrm{d}_{130}, 200\right)$ and $2 \theta=59.15^{\circ}\left(\mathrm{d}_{060}, 330\right)$. Using the Bragg's law $(\lambda=2 d \sin \theta)$, where $\lambda$ is the $\mathrm{Cu} \mathrm{K} \alpha$ incident radiation, $d$ is the interplane spacing (d-spacing) and $\theta$ is half the position of each peak, the interplane spacing can be determined. The position of the peaks is in good agreement with published data (Datta et al., 2007). The XRD pattern of the Mg aminoclay is characterized by a $\mathrm{d}_{001}$ spacing at $1.44 \mathrm{~nm}$ due to the presence of the aminopropyl organic chains between layers. The XRD profile also showed retention of the typically highly disordered in-plane organoclay reflections $\left(\mathrm{d}_{020}, 110, \mathrm{~d}_{130}, 300\right)$, as well as the characteristic phyllosilicate peak at $2 \theta=59.15^{\circ}\left(d_{060,330}=0.156\right.$ $\mathrm{nm}$ ), confirming the formation of 2:1 trioctahedral $\mathrm{Mg}$-phyllosilicate clay with talc-like structure. These aminoclays have a structure analogous to 2:1 trioctahedral smectites, such as talc, but are covalently linked with the approximate composition $\mathrm{R}_{8} \mathrm{Si}_{8} \mathrm{Mg}_{6} \mathrm{O}_{16}(\mathrm{OH})_{4}$, where $\mathrm{R}$ $=\mathrm{CH}_{2} \mathrm{CH}_{2} \mathrm{NH}_{2}$. The structure is composed of octahedrally coordinated brucite layers sandwiched between tetrahedral organosilicate networks.

\subsection{Transformation of E. coli JM109 with pUC19 plasmid using $M g$ aminoclays}

The transformation efficiency showed an increase from $0.1 \mathrm{mg} / \mathrm{mL}$ and $1 \mathrm{mg} / \mathrm{mL}$ to $10 \mathrm{mg} / \mathrm{mL} \mathrm{Mg}$ aminoclays in distilled water (Fig. 4a). The mean transformation efficiency values increased from 85 and 78 $\mathrm{CFU} / \mu \mathrm{g}$ pUC19 respectively to $1.3 \times 10^{3} \mathrm{CFU} / \mu \mathrm{g}$ pUC19. This assay was performed with petri dishes containing $2 \%$ agar and $2 \%$ LB. A stock solution of $10 \mathrm{mg} / \mathrm{mL} \mathrm{Mg}$ aminoclays in distilled water was prepared, which was used in all the following optimization assays. This particular assay was performed with $2 \%$ agar, $\mathrm{OD}_{600}=1.0$ and spreading time of $30 \mathrm{~s}$.

The agar hardness was varied (1-4\%) to ascertain the effect of friction on transformation efficiency on $E$ coli JM109/pUC19/Mg aminoclays suspension (Fig. 4b). All Petri dishes were prepared with $2 \%$ LB. The transformation efficiency is higher for $1 \%$ and $2 \%$ agar even though transformation also occurred at agar concentrations of 3\% and $4 \%$. The average efficiency at $2 \%$ agar was $3.2 \times 10^{3} \mathrm{CFU} / \mu \mathrm{g}$ pUC19 and for $1 \%$ agar was $2.2 \times 10^{3} \mathrm{CFU} / \mu \mathrm{g}$ pUC19. The experiment was performed with a spreading time of $30 \mathrm{~s}$ and an optical density of cells of $1.0\left(\mathrm{OD}_{600}=\right.$ 1.0).

The transformation efficiency is higher at the exponential growth phase and at the stationary growth phase (Fig. 4c). The average transformation efficiency for $\mathrm{OD}_{600}=0.7$ is $4.9 \times 10^{3} \mathrm{CFU} / \mu \mathrm{g}$ pUC19 and for $\mathrm{OD}_{600}=1.5$ the average transformation efficiency is $2.2 \times 10^{3} \mathrm{CFU} / \mu \mathrm{g}$ pUC19. The spreading time used was $30 \mathrm{~s}$ for all optical densities tested under this assay and the agar concentration used was $2 \%$.

Different spreading times were examined for the E coli JM109/ pUC19/Mg aminoclays suspension on $2 \%$ agar/LB Petri dishes (30, 60 and $90 \mathrm{~s}$ ) (Fig. 4d). The cell optical density used in this assay was 1.0 $\left(\mathrm{OD}_{600}=1.0\right)$. Contrary to what was found with sepiolite, in which the best spreading time for manual spreading was $30 \mathrm{~s}$ (Mendes et al., 2015), the best spreading time for $\mathrm{Mg}$ aminoclays was 60 and $90 \mathrm{~s}$. For $60 \mathrm{~s}$ the mean efficiency of transformation obtained was $5.9 \times 10^{3} \mathrm{CFU} / \mu \mathrm{g}$
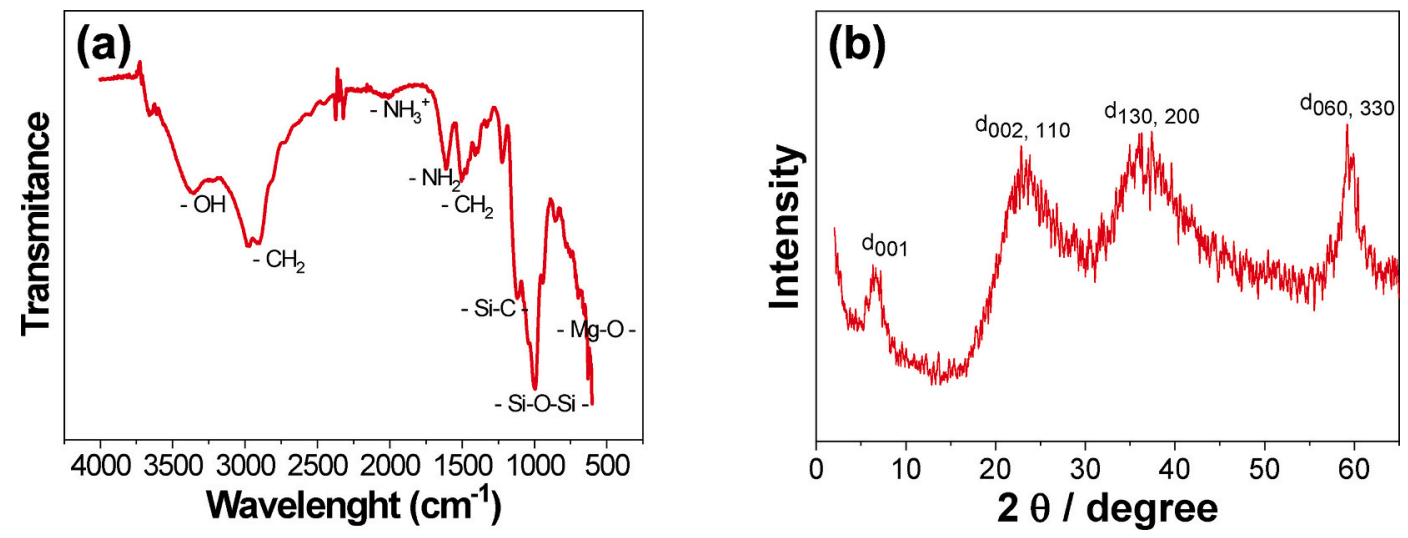

Fig. 3. (a) ATR-FTIR and (b) XRD of Mg aminoclays. 
(a)

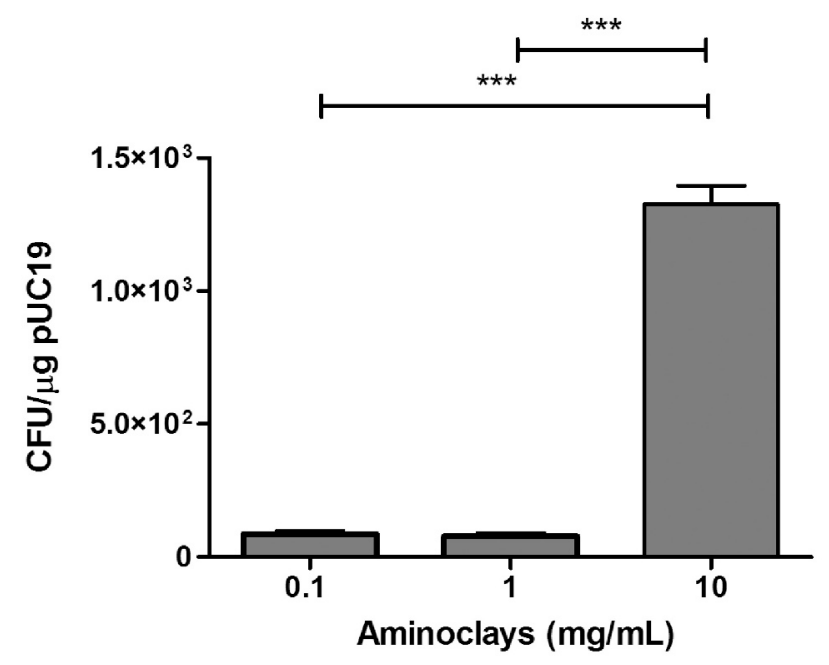

(c)

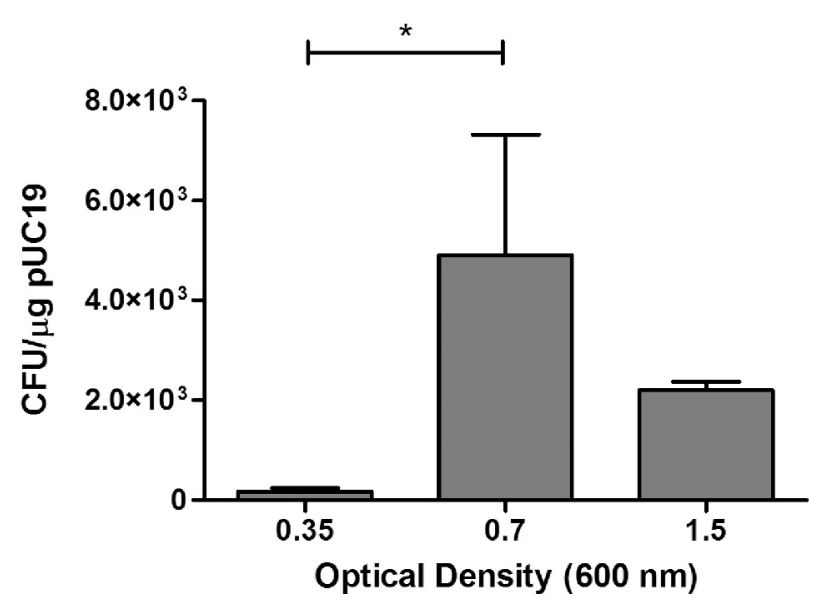

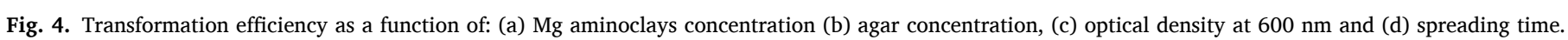

(b)

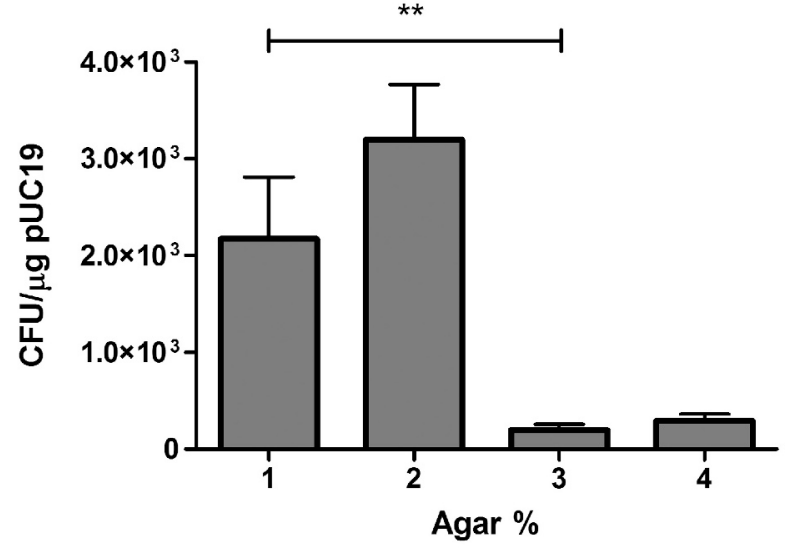

(d)

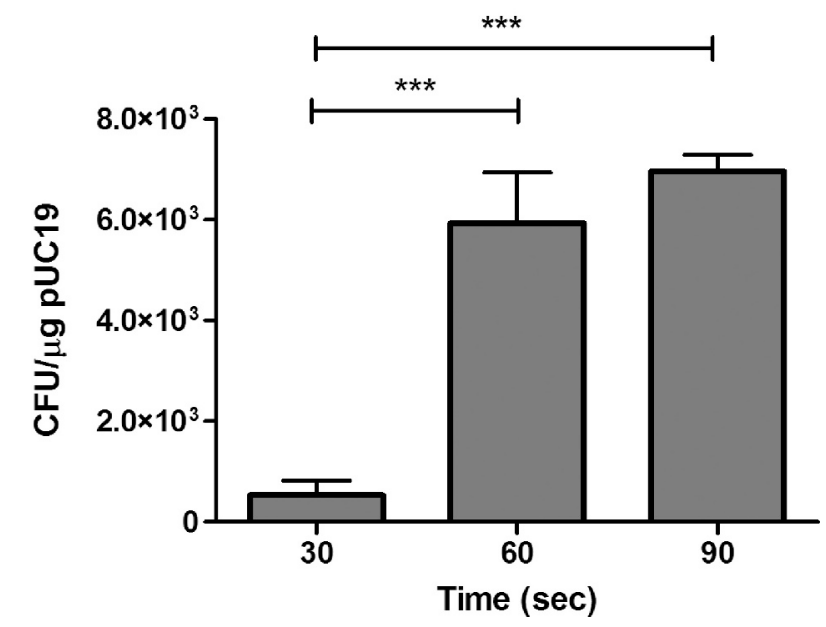

pUC19. For $90 \mathrm{~s}$, the mean efficiency of transformation reached a value of $7.0 \times 10^{3} \mathrm{CFU} / \mu \mathrm{g}$ pUC19 and this was the highest transformation efficiency obtained after all experimental adjustments.

The maximum value of transformation efficiency obtained in this work is lower than the one obtained with the same host and plasmid using sepiolite through the Yoshida effect (transformation by penetration of nano and micro-sized fibers that form permeation intermediates due to friction on a hydrogel), which achieved a transformation efficiency of $4.1 \times 10^{4} \mathrm{CFU} / \mu \mathrm{g}$ pUC19 and also does not require the usage of competent cells (Mendes et al., 2015). However, Mg aminoclays are a more user friendly and adequate material than sepiolite and other alternatives for being employed as delivery agents as will be further discussed in this section. A considerably high transformation efficiency has also been achieved using sepiolite as delivery agents for the transformation of Salmonella typhimurium LT2 $\left(\sim 5 \times 10^{5} \mathrm{CFU} / \mu \mathrm{g}\right.$ pUC19) (Elabed et al., 2016). An improvement of the sepiolite approach has recently been proposed on the XL2-Blue strain of E. coli with pUC19 plasmid through the inclusion of a one-hour incubation step in HEPES or Tris buffer of the DNA/sepiolite complex with the bacteria prior to spreading (Castro-Smirnov et al., 2020). On this work, the effect of $\mathrm{MgCl}_{2}, \mathrm{CaCl}_{2}$, spermidine and sonication of sepiolite prior assembly with
DNA was also addressed and the maximum value of transformation efficiency reported was $9 \times 10^{5}$ transformants per $\mu \mathrm{g}$ pUC19 with the inclusion of the extra one-hour incubation step and the pre-sonication of sepiolite, which was considered a more than ten-fold increase in transformation efficiency when compared with the value obtained using the standard sepiolite transformation protocol on the same host as control. The inclusion of divalent cations or spermidine in a transformation approach combined with a plasmid delivery agent is regarded as a convenient innovation with promising benefits and is foreseen to produce a positive contribution in future work dedicated to transformation of microorganisms using $\mathrm{Mg}$ aminoclays or other delivery agents when used accordingly. However, although a small improvement in transformation efficiency was obtained by the inclusion of some of the other variables, the extra one-hour incubation step in buffer and the presonication that resulted in a ten-fold transformation increase also constitutes a drawback relative to the previous straightforward bacterial transformations using sepiolite since the whole process is less convenient and more time-consuming and its implementation should be pondered beforehand.

The employment of cationic cell penetrating peptides (Toyohara et al., 2019) holds great potential for the delivery of large-sized 
plasmids, however this approach is not directly comparable to the approach presented in this work since a different strain was transformed (E. coli DH5 $\alpha$ ), but especially because of the extremely large size plasmid that was used (pMSR227, $205 \mathrm{~kb}$ ), resulting in a very low transformation efficiency ( $\sim 8 \mathrm{CFU} / \mu \mathrm{g}$ DNA) (Islam et al., 2019). Another approach using arginine-glucose functionalized hydroxyapatite nanoparticles and a $10 \mathrm{~kb}$ plasmid has achieved very high transformation efficiencies on Escherichia coli DH5 $\alpha\left(10^{9} \mathrm{CFU} / \mu \mathrm{g}\right.$ of DNA), Staphylococcus aureus MTCC 737 ( $10^{7} \mathrm{CFU} / \mu \mathrm{g}$ of DNA) (Deshmukh et al., 2019a) and Candida albicans $183\left(10^{6} \mathrm{CFU} / \mu \mathrm{g}\right.$ of DNA) (Deshmukh et al., 2019b) which is very promising even though a direct comparison with the results reported herein cannot be made without taking into account the fact that different hosts and plasmids were employed. Despite the promising efficiency results, these functionalized nanoparticles are more expensive than aminoclays to synthesize, requiring also a much more complicated and laborious process than $\mathrm{Mg}$ aminoclays and a more accident susceptible manipulation of dangerous reagents. Safety and simplicity in producing the delivery agent material is essential for a widespread adoption of a new transformation approach based on convenience. $\mathrm{Mg}$ aminoclays synthesis basically requires a one-step injection of a small amount of APTES into ethanol using a syringe, continuous overnight stirring followed by washing and $40{ }^{\circ} \mathrm{C}$ drying. Thereby, $\mathrm{Mg}$ aminoclays can be produced through a much faster, safer and simpler process and the transformation efficiency obtained in this work is high enough for many common cloning purposes whereby the amount of plasmid available for the assay in not too low. For instance, an assay using $10 \mathrm{ng}$ of plasmid is expected to originate 70 transformants per Petri dish, which is optimal for conventional CFU counting that typically lies in the $30-300$ range of colonies per standard agar Petri dish of $8 \mathrm{~cm}$ in diameter (Sieuwerts et al., 2008). Additionally, despite the fact that hydroxyapatite nanoparticles have been shown to be biocompatible and have been used for several biomedical applications (Turon et al., 2017), the safety and toxicity of the type reported for the transformation of microorganisms has still not been properly scrutinized. The cytotoxicity and hazards or risks requirements should therefore be tested before a widespread adoption of this material for the transformation of microorganisms is implemented.

There is evidence that a specific type of sepiolite used for transformation of microorganisms does not induce carcinogenesis in rats, considering the injection experiments that investigated its potential to generate peritoneal mesotheliomas (Rodelsperger et al., 1987). In fact, it has been demonstrated that sepiolite does not lead to significant unscheduled DNA synthesis-induction in rat hepatocytes (Denizeau et al., 1985). The International Agency for Research on Cancer (IARC) has consider that sepiolite cannot be classified as to its carcinogenicity to humans (Group 3), based on inadequate evidence in humans for the carcinogenicity of sepiolite, limited evidence in experimental animals for the carcinogenicity of long sepiolite fibers $(>5 \mathrm{~mm}$ ) and inadequate evidence in experimental animals for the carcinogenicity of short sepiolite fibers ( $<5 \mathrm{~mm}$ ) (IARC, 1997). Moreover, it has been proven that sepiolite can cause a significant increase of the oxidative stress in hamster and rat alveolar macrophages which are effectors of mineralinduced lung disease (Hansen and Mossman, 1987; Maisanaba et al., 2015), and since the biological implications of Reactive Oxygen Species (ROS) production is not consensual (there is evidence for harmful and beneficial effects for human health (Pizzino et al., 2017)), moderate caution is advisable for high exposure to ROS stimulating material such as sepiolite.

In contrast, it has been demonstrated that $\mathrm{Mg}$ aminoclays have very little cytotoxicity to various types of human cell lines as verified by MTT and LDH assays, not inducing apoptosis up to concentrations as high as $1000 \mu \mathrm{g} / \mathrm{mL}$ (Han et al., 2011) and Mg aminoclay nanoparticles have shown to present low risk for long-term tissue accumulation in mice models following oral administration (Yang et al., 2014), being very safe to manipulate after preparation without specific safety measures or equipment. It only requires a syringe to ensure a safe manipulation of
APTES during synthesis. Sepiolite is a more robust transformation material with more reports in the literature than arginine-glucose functionalized hydroxyapatite nanoparticles and has a 5.9 times higher transformation efficiency than $\mathrm{Mg}$ aminoclays using the same host and plasmid (Mendes et al., 2015). However, Mg aminoclays have a higher potential than sepiolite for acquiring enhanced properties that can become a complement to transformation of microorganisms as it has been demonstrated in their use as biosensors (Mann, 2009; Mousty, 2010; Song et al., 2018) or drug delivery nanocarriers (Patil et al., 2005; Patil and Mann, 2008; Chaturbedy et al., 2010; Silva Filho, 2019), making aminoclay-based materials more promising for future implementations of DNA delivery agents since these additional properties can potentially be exploited synergistically with transformation during interaction with cells.

The transformation efficiency obtained in this work is higher than the value obtained in previous reports using $\mathrm{Mg}$ aminoclays for transformation of Paenibacillus riograndensis SBR5 $\left(1.1 \times 10^{3} \mathrm{CFU} / \mu \mathrm{g}\right.$ pNW33Nmp and $1.8 \times 10^{3} \mathrm{CFU} / \mu \mathrm{g}$ pTE), Paenibacillus polymyxa DSM$365\left(\sim 10^{2} / \mu \mathrm{g}\right.$ pNW33Nmp and $\sim 10^{2} / \mu \mathrm{g}$ pTE) (Brito et al., 2017) and Streptococcus mutans KCTC $3065\left(\sim 6 \times 10^{3} \mathrm{CFU} / \mu \mathrm{g}\right.$ pBBR122) (Choi et al., 2013) but inferior than for transformation of E. coli XL1-Blue $\left(\sim 2 \times 10^{5} \mathrm{CFU} / \mu \mathrm{g}\right.$ pBBR122) (Choi et al., 2013). This variation in maximum transformation efficiency reported is not unexpected since the host and/or plasmid used are different, and most importantly, all the values of transformation efficiency achieved are still high enough for many common transformation proposes if the amount of plasmid available is not a limiting factor such as can be the case as in strain construction. Moreover, obtaining high transformation efficiency is not always the main concern as in the context where the purpose is simply to be able to transform a recalcitrant microorganism with biotechnological potential, whereby a plasmid delivery agent approach such as the one optimized in this work may become fundamental for overcoming the present difficulties that the conventional transformation approaches heat-shock and electroporation do not solve. The fine-tuning of different variables that influence transformation efficiency presented in this work also contributes to a better understanding of the conditions required for a successful transformation of recalcitrant microorganisms that delivery agents have potential to enable.

Despite reports of other methods using DNA delivery agents with similar or even superior efficiency values, the novelty and benefits of a transformation approach are also measured by the cost of the starting materials, the difficulties and safety of production of the delivery agent, health and environmental implications that follow a prolonged or extensive use of all the materials involved and, finally, practical advantages for the end user such as retail price, time gain, level of skills required and fulfillment of several safety and hazardous requirements in comparison to competing methods. The production of $\mathrm{Mg}$ aminoclays is more cost-effective, simpler and requires a lower level of safety measures than the production of arginine-glucose functionalized hydroxyapatite nanoparticles (Deshmukh et al., 2019a, 2019b). As for the end user, since the procedure presented in this work is already optimized and very simple, basically just requiring 1 min mixing for complex formation and 1 min mixing of the DNA-Mg aminoclay complexes with cells followed by spreading into Petri dishes (which avoids any prolonged intermediate steps such as incubation for complexation), it is more userfriendly in terms of time and skills required than other competing methods. Moreover, at present date, $\mathrm{Mg}$ aminoclay nanoparticles are the only emergent transformation material that has been analyzed by highlevel ecotoxicity and environmental safety tests (Choi et al., 2014), which indicated a good environmental acceptability. Additionally, since aminoclay-based delivery agents are a well-established entity for intercalation of biomolecules through self-assembly of exfoliated sheets or by wrapping and encapsulation (Patil et al., 2005, 2007; Patil and Mann, 2008; Bui et al., 2018), they hold higher potential than sepiolite or arginine-glucose functionalized hydroxyapatite nanoparticles to be synergistically used as delivery agents of other compounds such as 
proteins. Mg aminoclays can also be easily conjugated with molecules containing carboxylic groups using straightforward protocols from commercial kits based on 1-ethyl-3-(3-dimethylaminopropyl)carbodiimide - N-hydroxysuccinimide (EDC-NHS) chemistry due to the presence of pendant amino groups, and can originate intracellular biosensors (Lee et al., 2013b; Kang et al., 2015), which can then be employed as probes enabling new variables to be examined during transformation. Therefore, the use of $\mathrm{Mg}$ aminoclays for transformation of microorganisms is a very innovative, promising and advantageous approach compared to other emergent or conventional strategies.

\subsection{Confirmation of pUC19/E. coli JM109 transformation by agarose gel electrophoresis}

The plasmid pUC19 is a widely used vector in molecular biology. Apart from having a high copy number and encoding for an ampicillin resistance gene it has a well-designed multiple cloning site (MCS) providing restriction sites for many restriction endonucleases and the hosts into which a hypothetical foreign DNA insertion is introduced can be easily distinguished from the non-recombinant hosts just by comparing the color of new colonies on the growth media due to activity of the $\beta$-galactosidase (lacZ) gene that is inactivated by the insertion. Plain pUC19 was used as a proof-of-concept without any DNA insertion in the MCS, so the transformed colonies were expected to grow only in blue color in the presence of a medium supplemented with IPTG and Xgal due to $\alpha$-complementation. In a typical assay for confirming that transformation did indeed occur with pUC19, four colonies were randomly picked from a group of colonies belonging to an agar containing Petri dish that was previously used in a transformation assay. These colonies were grown in the presence of ampicillin, IPTG and X-gal presenting blue color (Fig. 5a). No white colonies ever grew on the Petri dishes, indicating that no non-transformed bacteria survived the presence of ampicillin and that the pUC19 plasmid was stable, suggesting that transformation using the approach presented in this work did not induce mutagenic behavior. The four colonies were transferred to four individual falcons containing $5 \mathrm{~mL}$ of LB and $100 \mu \mathrm{g} / \mathrm{mL}$ ampicillin and E. coli was left growing in liquid overnight. During the following day, the plasmid was extracted from each sample and an agarose gel was run to confirm the size of the plasmid (Fig. 5b). pUC19 has 2686 bps and was linearized by EcoRV and HindIII. As can be seen in Fig. 5b, the digested plasmids migrated to just below the $3 \mathrm{~kb}$ band of the DNA marker ladder confirming that the isolated plasmid is indeed pUC19. This finding combined with the transformants' double-checked resistance to ampicillin and the ability to display blue colonies in the presence of Xgal (Fig. 5a), proved that the transformation assays occurred successfully.

\section{Conclusions}

$\mathrm{Mg}$ aminoclays were synthesized and characterized by TEM, ATRFTIR, XRD, DLS and zeta potential and were used to deliver the pUC19 plasmid and transform E coli JM109 in a rapid, convenient and risk-free procedure, revealing potential to become a common and inexpensive laboratory resource for routine transformation purposes. Several parameters were optimized, namely $\mathrm{Mg}$ aminoclays concentration, agar concentration on Petri dishes, bacterial phase of growth and spreading time of the $\mathrm{Mg}$ aminoclays/E. coli/plasmid mixture. The maximum average transformation efficiency achieved was $7.0 \times 10^{3}$ $\mathrm{CFU} / \mu \mathrm{g}$ pUC19 for $10 \mathrm{mg} / \mathrm{mL} \mathrm{Mg}$ aminoclays, $2 \%$ agar, optical density of $1.0\left(\mathrm{OD}_{600}=1.0\right)$ and a spreading time of $90 \mathrm{~s}$. This value is inferior than the efficiency of transformation of $E$. coli JM109 that can be obtained with a similar protocol using sepiolite fibers as delivery agents of the same plasmid ( $4.1 \times 10^{4} \mathrm{CFU} / \mu \mathrm{g}$ pUC19 (Mendes et al., 2015)), but is high enough for many common cloning circumstances and $\mathrm{Mg}$ aminoclays possess a higher potential than sepiolite to be used synergistically for other purposes, based on their biosensing or drug delivery potential. Moreover, $\mathrm{Mg}$ aminoclays can be synthesized in large quantities and can be stocked at room-temperature in a dry form or in solution for long periods of time in a similar fashion to sepiolite, enabling the transformation process to become much simpler and less timeconsuming than heat-shock or electroporation since no previous preparation of competent cells is required. Furthermore, the transformation procedure can be performed at room-temperature and does not require high-voltages. The success of transformation was triple checked by the growth of genetically modified blue colonies in the presence of ampicillin, regrowth of biomass in liquid media containing ampicillin and by agarose gel electrophoresis of the linearized plasmid extracted from transformed colonies. This work provides a robust alternative for transformation of $E$ coli JM109 under the experimental conditions used and can serve as a reference for future transformation attempts on less common cloning hosts or recalcitrant microorganisms, which is a fundamental challenge for researchers exploring the potential of biotechnology.
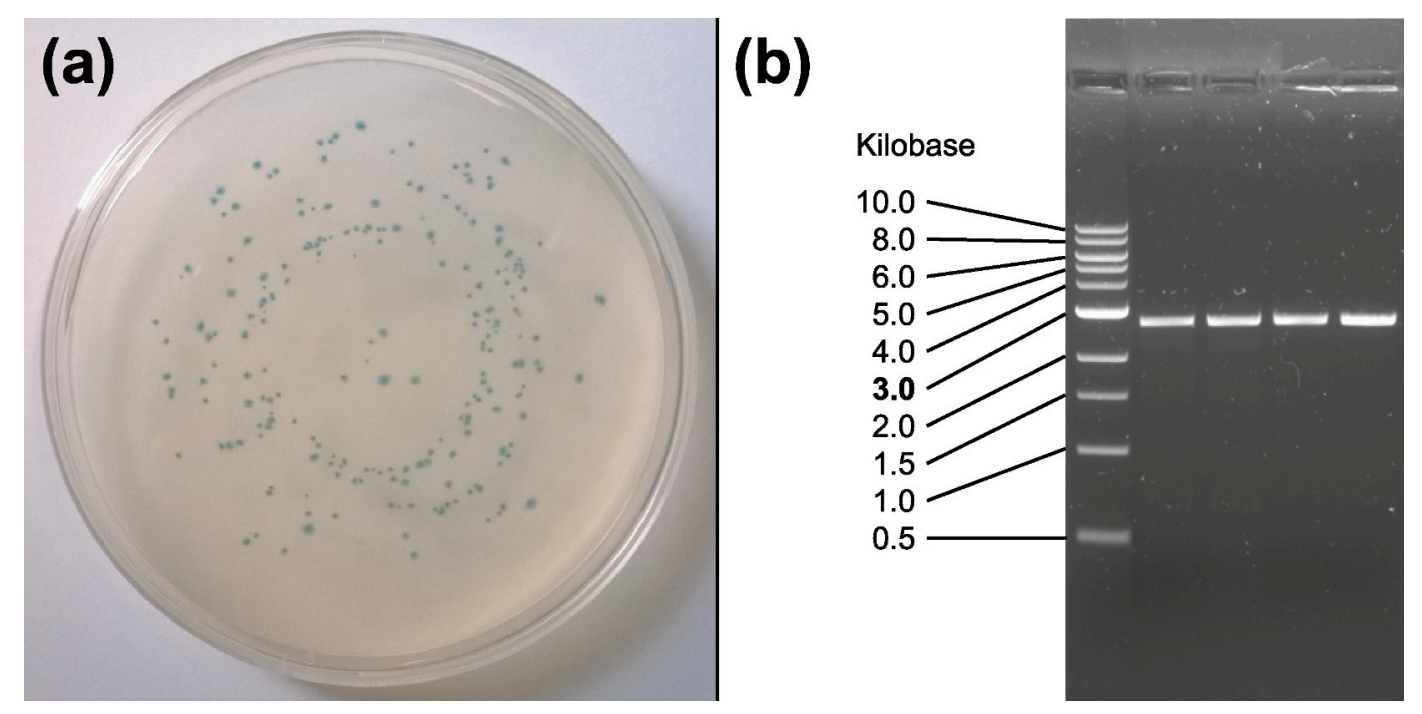

Fig. 5. (a) Representative image of a Petri dish of E. coli JM109 colonies transformed with pUC19 using Mg aminoclays. (b) Agarose gel electrophoresis of pUC19 cut with EcoRV (lanes 1 and 2) and HindIII (lanes 3 and 4). Lane 0 is from $1 \mathrm{~kb}$ DNA ladder. 


\section{Credit author statement}

All authors contributed to the study conception and design. Material preparation and data collection were performed by GPM. All authors analyzed data. SLM and MM contributed new reagents or analytical tools. The first draft of the manuscript was written by GPM and all authors commented on previous versions of the manuscript. All authors have given approval to the final version of the manuscript.

\section{Declaration of Competing Interest}

There are no conflicts to declare.

\section{Acknowledgements}

This study was supported by the Portuguese Foundation for Science and Technology (FCT) and the European Community fund FEDER, through Program COMPETE, under the scope of the Projects FCOMP-010124-FEDER-007025 (PTDC/AMB/68393/2006), PEst-OE/EQB/ LA0023/2013, UID/FIS/04650/2020, RECI/BBB-EBI/0179/2012 (FCOMP-01-0124-FEDER-027462) and the Project "BioEnv - Biotechnology and Bioengineering for a sustainable world". The authors acknowledge the fellowship SFRH/BD/71661/2010 awarded to Gabriel Mendes under the scope of the MIT-Portugal Program. The authors also thank Paul Brown and Takuya Harada for the help in obtaining TEM images.

\section{References}

Abhinayaa, R., Jeevitha, G., Mangalaraj, D., Ponpandian, N., Meena, P., 2019. Toxic influence of pristine and surfactant modified halloysite nanotubes on phytopathogenic bacteria. Appl. Clay Sci. 174, 57-68. https://doi.org/10.1016/j clay.2019.03.022.

Balazs, A.C., Emrick, T., Russell, T.P., 2006. Nanoparticle polymer composites: where two small worlds meet. Science. 314, 1107-1110. https://doi.org/10.1126/ science. 1130557.

Bonderer, L.J., Studart, A.R., Gauckler, L.J., 2008. Bioinspired design and assembly of platelet reinforced polymer films. Science. 319, 1069-1073. https://doi.org/ 10.1126/science.1148726.

Brito, L.F., Irla, M., Walter, T., Wendisch, V.F., 2017. Magnesium aminoclay-based transformation of Paenibacillus riograndensis and Paenibacillus polymyxa and development of tools for gene expression. Appl. Microbiol. Biotechnol. 101, 735-747. https://doi.org/10.1007/s00253-016-7999-1.

Bui, V.K.H., Park, D., Lee, Y.-C., 2018. Aminoclays for biological and environmental applications: an updated review. Chem. Eng. J. 336, 757-772. https://doi.org/ 10.1016/j.cej.2017.12.052.

Burkett, S.L., Press, A., Mann, S., 1997. Synthesis, characterization, and reactivity of layered inorganic-organic nanocomposites based on 2:1 trioctahedral phyllosilicates. Chem. Mater. 9, 1071-1073. https://doi.org/10.1021/cm9700615.

Castro-Smirnov, F.A., Piétrement, O., Aranda, P., Le Cam, E., Ruiz-Hitzky, E., Lopez, B.S., 2020. Biotechnological applications of the sepiolite interactions with bacteria: bacterial transformation and DNA extraction. Appl. Clay Sci. 191, 105613. https:// doi.org/10.1016/j.clay.2020.105613.

Chandrasekaran, G., Han, H.-K., Kim, G.-J., Shin, H.-J., 2011. Antimicrobial activity of delaminated aminopropyl functionalized magnesium phyllosilicates. Appl. Clay Sci. 53, 729-736. https://doi.org/10.1016/j.clay.2011.07.001.

Chaturbedy, P., Jagadeesan, D., Eswaramoorthy, M., 2010. pH-sensitive breathing of clay within the polyelectrolyte matrix. ACS Nano 4, 5921-5929. https://doi.org/ $10.1021 / \mathrm{nn} 100700 \mathrm{~b}$

Choi, H.A., Lee, Y.C., Lee, J.Y., Shin, H.J., Han, H.K., Kim, G.J., 2013. A simple bacterial transformation method using magnesium- and calcium-aminoclays. J. Microbiol. Methods 95, 97-101. https://doi.org/10.1016/j.mimet.2013.07.018.

Choi, M.H., Hwang, Y., Lee, H.U., Kim, B., Lee, G.W., Oh, Y.K., Andersen, H.R., Lee, Y.C., Huh, Y.S., 2014. Aquatic ecotoxicity effect of engineered aminoclay nanoparticles. Ecotoxicol. Environ. Saf. 102, 34-41. https://doi.org/10.1016/j. ecoenv. 2014.01.005.

Datta, K.K.R., Eswaramoorthy, M., Rao, C.N.R., 2007. Water-solubilized aminoclay-metal nanoparticle composites and their novel properties. J. Mater. Chem. 17, 613-615. https://doi.org/10.1039/B617198B.

Datta, K.K.R., Achari, A., Eswaramoorthy, M., 2013. Aminoclay: a functional layered material with multifaceted applications. J. Mater. Chem. A 1, 6707. https://doi.org/ 10.1039/c3ta00100h.

Demanèche, S., Jocteur-Monrozier, L., Quiquampoix, H., Simonet, P., 2001. Evaluation of biological and physical protection against nuclease degradation of clay-bound plasmid DNA. Appl. Environ. Microbiol. 67, 293-299. https://doi.org/10.1128/ AEM.67.1.293-299.2001.
Denizeau, F., Marion, M., Chevalier, G., Cote, M.G., 1985. Absence of genotoxic effects of nonasbestos mineral fibers. Cell Biol. Toxicol. 1, 23-32. https://doi.org/10.1007/ BF00717788.

Deshmukh, K., Ramanan, S.R., Kowshik, M., 2019a. Novel one step transformation method for Escherichia coli and Staphylococcus aureus using arginine-glucose functionalized hydroxyapatite nanoparticles. Mater. Sci. Eng. C 96, 58-65. https:// doi.org/10.1016/j.msec.2018.10.088.

Deshmukh, K., Ramanan, S.R., Kowshik, M., 2019b. A novel method for genetic transformation of $C$. albicans using modified-hydroxyapatite nanoparticles as a plasmid DNA vehicle. Nanoscale Adv. 1, 3015-3022. https://doi.org/10.1039/ C8NA00365C.

Ding, X., Henrichs, S.M., 2002. Adsorption and desorption of proteins and polyamino acids by clay minerals and marine sediments. Mar. Chem. 77, 225-237. https://doi. org/10.1016/S0304-4203(01)00085-8.

Elabed, H., Hamza, R., Bakhrouf, A., Gaddour, K., 2016. Rapid DNA transformation in Salmonella Typhimurium by the hydrogel exposure method. J. Microbiol. Methods 126, 67-71. https://doi.org/10.1016/j.mimet.2016.04.017.

Gaálová, B., Vyletelová, I., Pokorná, K., Kikhney, J., Moter, A., Bujdák, J., Bujdáková, H., 2019. Decreased vitality and viability of Escherichia coli isolates by adherence to saponite particles. Appl. Clay Sci. 183, 105316. https://doi.org/10.1016/j. clay.2019.105316.

Ghodrati, M., Mousavi-Kamazani, M., Zinatloo-Ajabshir, S., 2020. $\mathrm{Zn}_{3} \mathrm{~V}_{3} \mathrm{O}_{8}$ Nanostructures: facile hydrothermal/solvothermal synthesis, characterization, and electrochemical hydrogen storage. Ceram. Int. 46, 28894-28902. https://doi.org/ 10.1016/j.ceramint.2020.08.057.

Han, H.-K., Lee, Y.-C., Lee, M.-Y., Patil, A.J., Shin, H.-J., 2011. Magnesium and calcium organophyllosilicates: synthesis and in vitro cytotoxicity study. ACS Appl. Mater. Interfaces 3, 2564-2572. https://doi.org/10.1021/am200406k.

Hansen, K., Mossman, B.T., 1987. Generation of superoxide $\left(\mathrm{O}_{2}^{-}\right)$from alveolar macrophages exposed to asbestiform and nonfibrous particles. Cancer Res. 47, 1681-1686.

Hsu, R.-S., Chang, W.-H., Lin, J.-J., 2010. Nanohybrids of magnetic iron-oxide particles in hydrophobic organoclays for oil recovery. ACS Appl. Mater. Interfaces 2, 1349-1354. https://doi.org/10.1021/am100019t.

IARC, 1997. IARC monographs on the evaluation of carcinogenic risks to humans. Volume 68. Silica, some silicates, coal dust and Para-aramid fibril. World Health Organization, pp. 267-282.

Islam, M.M., Odahara, M., Yoshizumi, T., Oikawa, K., Kimura, M., Su'etsugu, M., Numata, K., 2019. Cell-penetrating peptide-mediated transformation of large plasmid DNA into Escherichia coli. ACS Synth. Biol. 8, 1215-1218. https://doi.org/ 10.1021/acssynbio.9b00055.

Ito, T., Okabe, K., Mori, M., 2018. Growth reduction of Microcystis aeruginosa by clay ball elution solution. Appl. Clay Sci. 162, 223-229. https://doi.org/10.1016/j. clay.2018.06.018.

Kang, K.S., Lee, H.U., Kim, M. Il, Park, S.Y., Chang, S.J., Park, J.H., Huh, Y.S., Lee, J., Yang, M., Lee, Y.C., Park, H.G., 2015. In-vitro cytotoxicity assessment of carbonnanodot-conjugated $\mathrm{Fe}$-aminoclay $(\mathrm{CD}-\mathrm{FeAC})$ and its bio-imaging applications. J. Nanobiotechnology 13, 88. https://doi.org/10.1186/s12951-015-0151-z.

Kim, S., Lee, Y.-C., Cho, D.-H., Lee, H.U., Huh, Y.S., Kim, G.-J., Kim, H.-S., 2014. A simple and non-invasive method for nuclear transformation of intact-walled Chlamydomonas reinhardtii. PLoS One 9, e101018. https://doi.org/10.1371/journal. pone.0101018.

Kim, S.-Y., Lee, S.-J., Han, H.-K., Lim, S.-J., 2017. Aminoclay as a highly effective cationic vehicle for enhancing adenovirus-mediated gene transfer through nanobiohybrid complex formation. Acta Biomater. 49, 521-530. https://doi.org/ 10.1016/j.actbio.2016.11.045.

Lee, Y.C., Choi, Y.S., Choi, M., Yang, H., Liu, K., Shin, H.J., 2013a. Dual-end functionalized magnesium organo-(phyllo)silicates via co-condensation and its antimicrobial activity. Appl. Clay Sci. 83-84, 474-485. https://doi.org/10.1016/j. clay.2012.10.007.

Lee, Y.C., Kim, M. Il, Woo, M.A., Park, H.G., Han, J.I., 2013b. Effective peroxidase-like activity of a water-solubilized Fe-aminoclay for use in immunoassay. Biosens. Bioelectron. 42, 373-378. https://doi.org/10.1016/j.bios.2012.10.092.

Lee, Y.-C., Lee, T.-H., Han, H.-K., Go, W.J., Yang, J.-W., Shin, H.-J., 2010. Optical properties of fluorescein-labeled organoclay. Photochem. Photobiol. 86, 520-527. https://doi.org/10.1111/j.1751-1097.2009.00701.x.

Lee, Y.-C., Chang, S.-J., Choi, M.-H., Jeon, T.-J., Ryu, T., Huh, Y.S., 2013. Self-assembled graphene oxide with organo-building blocks of Fe-aminoclay for heterogeneous Fenton-like reaction at near-neutral $\mathrm{pH}$ : a batch experiment. Appl. Catal. B Environ. 142-143, 494-503. https://doi.org/10.1016/j.apcatb.2013.05.066.

Li, G.L., Zhou, C.H., Fiore, S., Yu, W.H., 2019. Interactions between microorganisms and clay minerals: new insights and broader applications. Appl. Clay Sci. 177, 91-113. https://doi.org/10.1016/j.clay.2019.04.025.

Liu, M., Wu, C., Jiao, Y., Xiong, S., Zhou, C., 2013. Chitosan-halloysite nanotubes nanocomposite scaffolds for tissue engineering. J. Mater. Chem. B 1, 2078. https:// doi.org/10.1039/c3tb20084a.

Liu, M., Shen, Y., Ao, P., Dai, L., Liu, Z., Zhou, C., 2014. The improvement of hemostatic and wound healing property of chitosan by halloysite nanotubes. RSC Adv. 4, 23540-23553. https://doi.org/10.1039/C4RA02189D.

Maisanaba, S., Pichardo, S., Puerto, M., Gutiérrez-Praena, D., Cameán, A.M., Jos, A., 2015. Toxicological evaluation of clay minerals and derived nanocomposites: a review. Environ. Res. 138, 233-254. https://doi.org/10.1016/j.envres.2014.12.024.

Mann, S., 2009. Self-assembly and transformation of hybrid nano-objects and nanostructures under equilibrium and non-equilibrium conditions. Nat. Mater. 8, 781-792. https://doi.org/10.1038/nmat2496. 
Mann, S., Burkett, S.L., Davis, S.A., Fowler, C.E., Mendelson, N.H., Sims, S.D., Walsh, D., Whilton, N.T., 1997. Sol-gel synthesis of organized matter. Chem. Mater. 9 , 2300-2310. https://doi.org/10.1021/cm970274u.

Mendes, G.P., Vieira, P.S., Lanceros-Méndez, S., Kluskens, L.D., Mota, M., 2015. Transformation of Escherichia coli JM109 using pUC19 by the Yoshida effect. J. Microbiol. Methods 115, 1-5. https://doi.org/10.1016/j.mimet.2015.05.012.

Miao, S., Liu, Z., Han, B., Huang, J., Sun, Z., Zhang, J., Jiang, T., 2006. Ru Nanoparticles immobilized on montmorillonite by ionic liquids: a highly efficient heterogeneous catalyst for the hydrogenation of benzene. Angew. Chem. Int. Ed. 45, 266-269. https://doi.org/10.1002/anie.200502632.

Morassaei, M.S., Zinatloo-Ajabshir, S., Salavati-Niasari, M., 2017. $\mathrm{Nd}_{2} \mathrm{Sn}_{2} \mathrm{O}_{7}$ Nanostructures: new facile Pechini preparation, characterization, and investigation of their photocatalytic degradation of methyl orange dye. Adv. Powder Technol. 28 , 697-705. https://doi.org/10.1016/j.apt.2016.11.017.

Mousavi-Kamazani, M., Zinatloo-Ajabshir, S., Ghodrati, M., 2020. One-step sonochemical synthesis of $\mathrm{Zn}(\mathrm{OH})_{2} / \mathrm{ZnV}_{3} \mathrm{O}_{8}$ nanostructures as a potent material in electrochemical hydrogen storage. J. Mater. Sci. Mater. Electron. 31, 17332-17338. https://doi.org/10.1007/s10854-020-04289-4.

Mousty, C., 2010. Biosensing applications of clay-modified electrodes: a review. Anal. Bioanal. Chem. 396, 315-325. https://doi.org/10.1007/s00216-009-3274-y.

Munch, E., Launey, M.E., Alsem, D.H., Saiz, E., Tomsia, A.P., Ritchie, R.O., 2008. Tough, bio-inspired hybrid materials. Science. 322, 1516-1520. https://doi.org/10.1126/ science.1164865.

Pappas, T.C., Wickramanyake, W.M.S., Jan, E., Motamedi, M., Brodwick, M., Kotov, N.A., 2007. Nanoscale engineering of a cellular interface with semiconductor nanoparticle films for photoelectric stimulation of neurons. Nano Lett. 7, 513-519. https://doi. org/10.1021/nl062513v.

Patil, A.J., Mann, S., 2008. Self-assembly of bio-inorganic nanohybrids using organoclay building blocks. J. Mater. Chem. 18, 4605-4615. https://doi.org/10.1039/ b805653f.

Patil, A.J., Muthusamy, E., Mann, S., 2005. Fabrication of functional protein-organoclay lamellar nanocomposites by biomolecule-induced assembly of exfoliated aminopropyl-functionalized magnesium phyllosilicates. J. Mater. Chem. 15, 3838-3843. https://doi.org/10.1039/b504288g.

Patil, A.J., Li, M., Dujardin, E., Mann, S., 2007. Novel bioinorganic nanostructures based on mesolamellar intercalation or single-molecule wrapping of DNA using organoclay building blocks. Nano Lett. 7, 2660-2665. https://doi.org/10.1021/nl071052q.

Pizzino, G., Irrera, N., Cucinotta, M., Pallio, G., Mannino, F., Arcoraci, V., Squadrito, F., Altavilla, D., Bitto, A., 2017. Oxidative stress: harms and benefits for human health Oxidative Med. Cell. Longev. https://doi.org/10.1155/2017/8416763.

Podsiadlo, P., Kaushik, A.K., Arruda, E.M., Waas, A.M., Shim, B.S., Xu, J., Nandivada, H., Pumplin, B.G., Lahann, J., Ramamoorthy, A., Kotov, N.A., 2007. Ultrastrong and stiff layered polymer nanocomposites. Science. 318, 80-83. https://doi.org/10.1126/ science.1143176.

Priolo, M.A., Gamboa, D., Holder, K.M., Grunlan, J.C., 2010. Super gas barrier of transparent polymer-clay multilayer ultrathin films. Nano Lett. 10, 4970-4974. https://doi.org/10.1021/nl103047k.

Ren, J., Karna, S., Lee, H.-M., Yoo, S.M., Na, D., 2019. Artificial transformation methodologies for improving the efficiency of plasmid DNA transformation and simplifying its use. Appl. Microbiol. Biotechnol. 103, 9205-9215. https://doi.org/ 10.1007/s00253-019-10173-x.

Rodelsperger, K., Bruckel, B., Manke, J., Woitowitz, H.J., Pott, F., 1987. Potential health risks from the use of fibrous mineral absorption granulates. Occup. Environ. Med. 44, 337-343. https://doi.org/10.1136/oem.44.5.337.
Ruiz-Hitzky, E., Darder, M., Aranda, P., 2005. Functional biopolymer nanocomposites based on layered solids. J. Mater. Chem. 15, 3650. https://doi.org/10.1039/ b505640n.

Scheuermann, G.M., Thomann, R., Mülhaupt, R., 2009. Catalysts based upon organoclay with tunable polarity and dispersion behavior: new catalysts for hydrogenation, $\mathrm{C}-\mathrm{C}$ coupling reactions and fluorous biphase catalysis. Catal. Lett. 132, 355-362. https:// doi.org/10.1007/s10562-009-0122-9.

Sieuwerts, S., de Bok, F.A.M., Mols, E., de Vos, W.M., van Hylckama Vlieg, J.E.T., 2008. A simple and fast method for determining colony forming units. Lett. Appl. Microbiol. 47, 275-278. https://doi.org/10.1111/j.1472-765X.2008.02417.x.

Silva Filho, E.C., 2019. Clays as biomaterials in controlled drug release: a scientific and technological short review. Biomed. J. Sci. Tech. Res. 15, 11237-11242. https://doi. org/10.26717/BJSTR.2019.15.002677.

Song, H., Lee, Y., Bui, V., Oh, Y.-K., Park, H., Kim, M., Lee, Y.-C., 2018. Effective peroxidase-like activity of Co-aminoclay [CoAC] and its application for glucose detection. Sensors (18), 457. https://doi.org/10.3390/s18020457.

Toyohara, D., Yokoi, Y., Inoue, G., Muraoka, T., Mori, T., 2019. Abiotic factors promote cell penetrating peptide permeability in Enterobacteriaceae models. Front. Microbiol. 10, 2534. https://doi.org/10.3389/fmicb.2019.02534.

Turon, P., del Valle, L., Alemán, C., Puiggalí, J., 2017. Biodegradable and biocompatible systems based on hydroxyapatite nanoparticles. Appl. Sci. 7, 60. https://doi.org/ 10.3390/app7010060.

Viseras, C., Cerezo, P., Sanchez, R., Salcedo, I., Aguzzi, C., 2010. Current challenges in clay minerals for drug delivery. Appl. Clay Sci. 48, 291-295. https://doi.org/ 10.1016/j.clay.2010.01.007.

Whilton, N.T., Burkett, S.L., Mann, S., 1998. Hybrid lamellar nanocomposites based on organically functionalized magnesium phyllosilicate clays with interlayer reactivity. J. Mater. Chem. 8, 1927-1932. https://doi.org/10.1039/a802120a.

Williams, L.B., Metge, D.W., Eberl, D.D., Harvey, R.W., Turner, A.G., Prapaipong, P., Poret-Peterson, A.T., 2011. What makes a natural clay antibacterial? Environ. Sci. Technol. 45, 3768-3773. https://doi.org/10.1021/es1040688.

Yang, L., Lee, Y.C., Kim, M. Il, Park, H.G., Huh, Y.S., Shao, Y., Han, H.K., 2014. Biodistribution and clearance of aminoclay nanoparticles: implication for in vivo applicability as a tailor-made drug delivery carrier. J. Mater. Chem. B 2, 7567-7574. https://doi.org/10.1039/c4tb00953c.

Yao, H.-B., Mao, L.-B., Yan, Y.-X., Cong, H.-P., Lei, X., Yu, S.-H., 2012. Gold nanoparticle functionalized artificial Nacre: facile in situ growth of nanoparticles on montmorillonite nanosheets, self-assembly, and their multiple properties. ACS Nano 6, 8250-8260. https://doi.org/10.1021/nn3029315.

Yoshida, N., Ide, K., 2008. Plasmid DNA is released from nanosized acicular material surface by low molecular weight oligonucleotides: exogenous plasmid acquisition mechanism for penetration intermediates based on the Yoshida effect. Appl. Microbiol. Biotechnol. 80, 813-821. https://doi.org/10.1007/s00253-008-1637-5.

Zhang, W., Li, M.K.S., Yue, P.-L., Gao, P., 2008. Exfoliated Pt-clay/Nafion nanocomposite membrane for self-humidifying polymer electrolyte fuel cells. Langmuir 24 , 2663-2670. https://doi.org/10.1021/la702153v.

Zhuk, A., Mirza, R., Sukhishvili, S., 2011. Multiresponsive clay-containing layer-by-layer films. ACS Nano 5, 8790-8799. https://doi.org/10.1021/nn202812a.

Zinatloo-Ajabshir, S., Salavati-Niasari, M., 2017. Facile synthesis of nanocrystalline neodymium zirconate for highly efficient photodegradation of organic dyes. J. Mol. Liq. 243, 219-226. https://doi.org/10.1016/j.molliq.2017.08.050.

Zinatloo-Ajabshir, S., Ghasemian, N., Mousavi-Kamazani, M., Salavati-Niasari, M., 2021. Effect of zirconia on improving NOx reduction efficiency of $\mathrm{Nd}_{2} \mathrm{Zr}_{2} \mathrm{O}_{7}$ nanostructure fabricated by a new, facile and green sonochemical approach. Ultrason. Sonochem. 71, 105376. https://doi.org/10.1016/j.ultsonch.2020.105376. 